The 'new normal' and 'new normalisations' in early childhood education policy in Aotearoa New Zealand:

Learnings from Covid-19

Andrew Gibbons

Auckland University of Technology

Marek Tesar

University of Auckland

When New Zealand entered pandemic alert level 3 and early childhood centres were being 'nudged' to re-open in order to offer support for parents returning to work, the Ministry of Health advised both Early Childhood centres and parents that children were not at risk of catching or spreading the virus. Fast-forward to Level 1 and the Ministry of Health has advised that an infant, who arrived into the country from overseas together with its parents, had the virus and was in a managed quarantine. This paper discusses this apparent policy contradiction between guidelines and evidence by collecting and analysing discourses that the nation has received from government agencies regarding children and early childhood education. This paper uses these discourses to explore the 'body' of knowledge regarding childhood and early childhood education, discourses that make childhood and early childhood education possible. We then apply a range of theoretical and conceptual tools to suggest some possible conditions of early childhood education (leading up to, during, and post-Covid-19). We employ health and medical metaphors to highlight ongoing tensions for early childhood education as a patient for whom neither education nor health Ministries take sufficient responsibility. The use of a health as a metaphor additionally focuses this paper on the new 'normal' of early childhood education and education policy.

Keywords: governmentality, normalisation, new normal, early childhood education, Covid-19

\title{
Introduction
}

The Covid-19 pandemic has revealed and reinforced the important and varied functions of early learning services in Aotearoa New Zealand. In 2020 services were provided with regular communications from the Ministry of Education regarding the nature of this contribution, as well as the risks posed by attendance of a service to children, teachers and communities. Those risks, and the Government's expectations regarding early learning services, were the topic of considerable media and public discussion (see, for instance, Gibbons, 2020). The presence of a range of often competing views and concerns is arguably very typical of the early childhood education sector and evidences the complex task of governing the education sector. When the complexity of responding to a global pandemic is added into the mix, a significant configuration of events and relationships invites exploration in order to better understand the sector and its governance. 
DOI: https://doi.org/10.26686/nzaroe.v25.6911

This paper focuses on the governance of the sector through an analysis of Government communications shared in Early Learning Bulletins provided for the sector by the Ministry of Education. In its analysis of the new normalisation, this paper engages with two arguments. The first is that the New Zealand Ministry of Education has a complex role in a robust democratic and participatory society with many perpetually competing expectations, responsibilities and contexts. The second is that if there is a 'new normal', then there is a 'new normalisation' (Jandric at al., 2020; Orchard et al., 2020; Peters et al., 2020). We problematise the 'new normal' as an invitation to explore how new normalisation operates. These ideas are explored through the selection of excerpts from Ministry of Education early childhood bulletins published between August and November 2020 in relation to Covid-19.

The bulletins provide examples to analyse for the ways in which the sector is constructed and governed. The analysis is informed by a reading of Foucault's work on governmentality, and in particular tensions between the governmental functions of normalisation, and the governmental aspirations for the politics of democracy. Moss (2015) highlights this tension:

... education and schools need not be reduced to institutions for regulating childhoods, to produce subjects fitted to the needs of a global market capitalism and participation in the global race. They can be something else; rather than normalisation and control, education and schools can be sites for democracy, emancipation and potentiality. (p. 232)

A focus on normalisation provides analysis of both overt and hidden understandings of the nature and purpose of the early childhood sector, and the ways in which the sector might manage itself based on these understandings. More than this, normalisation became a significant theoretical tool during the first six months of the pandemic due to the emergence of that now normalised phrase: 'the new normal', or sometimes even 'the new new normal' (see New Zealand Herald, 31 August 2020), linked to the governance personified by Prime Minister Jacinda Ardern and Director of Health Ashley Bloomfield.

In exploring instances of normalisation in early childhood education, the purpose of this paper is not simplistically to critique the governance of the sector. The use of Ministry of Education bulletins provides one of many possible glimpses through which the sector can engage with the complexities and practices of its own governance. In this sense we follow the suggestion of Karen Barad that critique has limited political potential for change (see, for instance, an interview with Juelskjær \& Schwennesen, 2012). The bulletins provided a lifeline at a critical time for services going through a wide range of states of emergency. We believe that analysis of the bulletins extends their use as a lifeline by offering points of departure for, to borrow a very well-known and normalised assessment phrase (Ministry of Education, 2004), noticing, recognising, and responding to the complexities of the sector.

\section{On normalisation}

In his insights on normalising education, educational philosopher llan Gur-Ze'ev explains that the "inner goal of any education is normalization of the subject in the service of reproducing the hegemonic sociocultural order and its realm of self-evidence. Within this setting, the legitimization of knowledge as well as the marginalization of knowledge of the 
DOI: https://doi.org/10.26686/nzaroe.v25.6911

other and her legitimization apparatuses is preconditions for social control, economic productivity, and well-protected cultural borders" (Gur-Ze'ev, 2017, pp. 1222-1223). Education is in its essence focused on the production and control of the subject's psyche, knowledge, self and relationships, through normalisation (Gur-Ze'ev, 2017). It is 'normal' for education systems to 'normalise' because the system has as its purpose the maintenance of certain ideas, beliefs, practices and relationships - the preservation of the status quo through the reification of a particular way of thinking and being and the oppression of alternatives. As such normalisation is a feature of what Foucault explores as 'governmentality'. Foucault's (1980) work on power/knowledge, biopower, governmentality, and technologies of the self has contributed to analysis of the production of the educated subject. In this framing, power's relationality is not explored as a simplistic assertion of a dominant or repressive subjection of individuals or groups, but rather as a relationality that produces the subject: often explained as the conduct of conduct. The focus is not on the role of the institution but in the relations of power exercised "in practice" (Fendler, 2017, p. 852). In other words, the focus is on exploring how "power is exercised" (Marshall, 1989, p. 103) throughout a political system, and in the daily lives of, in this case, the community of an early childhood centre. Through Foucault we can explore how power is exercised in the sector through the communications between the government and centres and owners and teachers, and with attention to how those communications conduct the conduct of centres and owners and teachers (Ailwood, 2003). As noted above, the emphasis on 'how' is particularly important to Foucault (Ailwood, 2003). For Fendler (2017):

Governmentality is neither a bad thing nor a good thing. Rather than regarding governmentality as a kind of power to be resisted in education, we can understand governmentality as a lens through which we recognize ourselves and the ways we behave. (p. 853)

However, the normalisation of populations through the elevation of the values and practices of a hegemony, and the oppression, marginalisation, or extinction of different values and practices, has warranted more than an impartial lens for the recognition of self. Indeed, the word normalisation is typically used pejoratively in the study of education (see, for instance, Tesar, 2014 on normalisation, governance, politics and childhoods). It would be arguably rare to read in government policy that the intention was to normalise the hegemony.

This resistance may in part be due to a key educational myth in, in this case, Aotearoa New Zealand. Namely, the purpose of education is believed to be the freedom of the learner. That freedom includes a freedom from the normalising tendencies of governments. Paradoxically, education is regarded as that which normalises the child and that which makes it possible for the child to choose their own pathways, their own relationships, their own knowledge, and their own ways of being (Malone et al., 2020). Fendler (2017) notes that "the notion of governmentality emphasizes that practices of freedom are themselves a form of governance ... governmentality is a term that allows us to talk about the norms by which we govern ourselves as free people" (p. 853). Hence, education systems which emphasise each student's (and teacher's) freedom to choose their experiences, contributions, and pathways (systems that recognise difference and complexity), require a normalisation of this way of understanding the nature and purpose of education. 
DOI: https://doi.org/10.26686/nzaroe.v25.6911

The notion of governmentality emphasises that the fullness of policy and practice are forms of governance. The Ministry of Education guidelines for policy and practice are instances of the technologies employed by government to produce particular subjects and to normalise particular views and expectations regarding education. For instance, the organising of the early childhood curriculum into three distinct ages would be one example of "disciplinary practices" that "are brought to bear on individuals for the purposes of normalization, examination, and observation" (Niesche, 2017, p. 839). So too can the early childhood regulations and licensing criteria be understood and theorised as normalising - although to say that a policy is normalising is, to follow the writers above, an unremarkable statement. The questions of significance include what's being normalised, by whom, for whom, for what purpose, with what implications, and, as noted above, how? These questions can be brought to bear not just on the somewhat concrete and static instances of policy and regulations, they can inform a reading of governmentality that is evident in the frequent communications from, in this case, the Ministry of Education to the sector in its Early Learning Bulletin.

\section{A selection of bulletin communications}

In this section we explore communications in the Early Learning Bulletins that are produced by the Ministry of Education in New Zealand and that are primarily directed towards managers and owners of early childhood services and organisations. We begin with the Bulletin on 4 August, 2020. In order to gather this data, all bulletins from March 2020 , and the first reference to the pandemic, were filed. In order to limit the volume of bulletins to analyse, we decided on a window of interest from August 2020 through to November 2020. Selecting this window allowed for five months of prior learning about the pandemic and the impact of lockdowns and covered multiple alert levels. Each bulletin was mined for specific references to the pandemic, and these were sorted into three recurring themes:

1. Participation and Learning

2. Health and Wellbeing

3. Myths and Realities

\section{Participation and learning}

The normalisation of participation in early childhood services was amplified in Government policy with the strategic plan in 2002 (Ministry of Education, 2002). The pandemic is a thorn in the side of participation and associated concerns about a loss of learning. In addressing these concerns, the bulletins highlighted strategies for learning from home and distance learning. For instance, in establishing guidelines for closure of centres the Ministry advised, on 15 August, that centres could be open for "distance learning." While distance learning has many manifestations, this particular idea of distance learning is arguably new to early childhood education and sets in motion new normalisations of the home and centre learning partnership. The letter template on 15 August included a space to add information about the centre's "distance learning programme." The 15 August bulletin also provided guidance on distance learning, with links to television programming. On 19 August the Ministry provides "Support for parents' conversations with their children." The Bulletin explained that the Ministry has developed 
DOI: https://doi.org/10.26686/nzaroe.v25.6911

these guidelines not just for talking about the virus but also for learning from home. In terms of the virus, the intention is to provide parents with "factual, age-appropriate information about Covid-19 so that they can feel informed and in control." Helping children and young people while they are learning at home, the Bulletin provided a link to the 'Nanogirl' video that provides an explanation of the virus, specifically designed for children. The 19 August Bulletin also provided a link to the "Hospital Play Specialists Association website" which "provides helpful advice about familiarising children with masks, helping children who are anxious and understanding Personal Protective Equipment (PPE)." On 5 October the Bulletin advised "With the entire country soon to be at Alert Level 1, we expect to see attendance levels improve again for all tamariki." It offers help to "develop strategies that will work for your context and community to help address attendance issues, or support well-being and engagement in learning." These intersecting concerns regarding wellbeing, learning and attendance highlight the key expectations of the sector and the role of the Ministry in providing any necessary guidance and resourcing to meet its expectations around participation.

With participation in early learning services a top educational priority, during the lockdowns the financial survival of centres was a primary concern for the Ministry. A dedicated Urgent Response Fund was initially articulated in terms of wellbeing and learning goals through supporting centres to be able to stay open through times with no or reduced participation. The emphasis on keeping services open so that children can continue to learn reiterated the government normalisation of early learning services as the preferred mechanism for all children's early learning. The Urgent Response Fund had been only intended for centre-based early learning services. The Bulletin explained on 19 August that that approach had been rethought due to feedback and a recognition that "children in home-based services may be experiencing Covid-19 related wellbeing challenges." On 14 September the emergency funding is explained not in terms of wellbeing and the continuation of learning but in terms of labour and employment:

The fund is to ensure sufficient capacity remains and continues to be available to support labour market participation as employment recovers. We want to ensure there are sufficient early learning services for children of parents who need to work or undertake study and retraining. The fund will also support the diversity and viability of services, particularly in low socio-economic areas or services that specifically cater for children from disadvantaged backgrounds.

The same fund then has two purposes, both of which can be seen as further contributing to the existing normalisation of the early childhood sector in relation to the normalisation of family life and family responsibilities (see, for instance, Smeyers, 2010). While the normalisation of early learning as a mechanism for governing the labour market might not be new, the normalisation of early learning as a mechanism for governing the labour market during a pandemic or crises of similar proportions is new and emphasises a new dimension to the potential and real contribution of the early childhood education sector.

On 15 August this emphasis on the importance of services being open focused on the supervision of children. At alert level 3, with tighter restrictions, those who "can attend an early learning service" are children "who can't be supervised at home by an appropriate person." These children need "to be able to attend early learning." There is a tension here between the use of early learning to characterise the service, but to talk about attendance in terms of supervision or the absence of it. Supervision is a key issue 
for families whose work is considered to be essential and/or frontline. A consideration of the importance of the essential and frontline workers is addressed in a later bulletin. On 24 November, the Ministry encouraged services to thank the "members of your community who are directly contributing to New Zealand's Covid-19 response including nurses and other medical professionals, border and defence force workers and security staff working in managed isolation facilities." These people are considered the "frontline defence against Covid-19" who have "ensured that more than 70,000 New Zealander's [sic] have been able to return safely home and kept us as safe from harm as possible." With a template provided, the Ministry's executive message appeared to be both undermining the frontline nature of teachers, their role in making it possible for frontline workers to do their job, and the initiative of teachers and parents to recognise each other without the prescription of the Ministry. This encouragement to thank essential members of the community emphasised the special nature of frontline work when contrasted to the expected, normalised contribution of early childhood teachers in supervising children so that their parents can directly contribute to the nation's safety.

On 27 August the wellbeing and learning narrative is revived in relation to attendance and participation, allowing that "some of your children will be reluctant to come back straight away." The Bulletin goes on to say "While there will have been loss of learning during the last couple of weeks, teacher and child wellbeing needs to come first. I know that you will be doing everything possible to re-engage children." The idea of loss of learning from a four week lock down is important to explore in terms of the normalisation of early childhood education, child development, and the roles of families. A view that a couple of weeks at home equates to a loss of learning does not gel well with the early childhood curriculum in a number of ways. For instance, the idea of learning at one's own pace, in their own time, is at odds with the idea of a loss that occurs during an absence from the centre. This framing of learning lost normalises a particular developmental approach to learning, constructs the time at home as lost time, and puts pressure on families and centres to return the child to the early learning service in order to minimise the apparent loss of learning. Here children's concerns about returning to an early learning services may become obstacles to the strategic aims regarding participation.

\section{Health and wellbeing}

Health and wellbeing in centres (and of centres) has long been a topic of debate that reflects competing views and evidence on the state of early childhood centres as healthy and well places to be, including views on ratios and physical space, temperature and hygiene, movements between centres, and the exclusion of sick children and adults some of which were recognised as essential dimensions to address in the recent action plan (Ministry of Education, 2019). All these elements have altered during the pandemic and communicated through the Bulletins. Some elements, such as hygiene practices, were largely stating what centres should be doing already in order to be licensed in addition to new practices such as removing hard to clean resources and prohibiting hard to clean spaces. Existing and new hygiene guidelines were regularly reiterated. On 12 August these included: "A reminder to have good cleaning practices in place" and "Soap and water is appropriate for washing hands, particularly if hand sanitiser stocks are low." One key and ongoing public health concern for early childhood centres has been the spread of communicable diseases. Hygiene practices have always been critical to prevent this 
spread. The emphasis on hygiene practices during this time raises questions as to just how normalised hygiene practices have been. On 3 November the Bulletin addressed an Auckland early learning services spike in norovirus cases which arguably came as something of a surprise given the intense attention to hygiene over the preceding months. "In recent outbreaks, up to a third of children and some staff have been ill with this type of gastroenteritis." "Maintaining good hand hygiene is the most important action to stop the spread of norovirus." At that stage, no mention is made of the apparent concerns with regards hygiene at a time when highly rigorous practices were the expected norm and were normalised through regular reiteration in the Bulletins. On 24 November further information revealed the challenges faced in normalising hygiene practices. With regard to the norovirus, the Bulletin advised that the "increase in reported norovirus outbreaks in New Zealand early learning services" may be "due to the increased use of alcohol-based hand sanitisers, which are not sufficient to kill some viruses associated with gastroenteritis, such as norovirus." In other words, the previous guidance with regards to the appropriateness of soap and water if hand sanitiser stocks are low, may have contributed to a view that hand sanitiser is preferable to hand washing. As such, the normalisation of hand sanitiser through the bulletins may have contributed to the spread of norovirus. Now, it's important here to take a moment to reiterate that the purpose here is not to criticise the Ministry for its work in communicating the importance of hygiene practices or for that matter the importance of the sector for the economy. Rather, the purpose is to explore which practices and beliefs become normalised, and how this normalisation occurs.

Other practices that were normalised during this time in order to prevent the spread of the virus revealed persistent challenges for the sector in terms of public health. For instance, the movement of children and teachers between groupings and centres revealed the impact of multiple learning service participation on health and wellbeing through the guidance for a new (if temporary) normalisation of prohibited movements. In addition to new guidelines around movement, the bulletins stressed the importance of new policies around the attendance of sick children and adults. On 12 August: "Please be alert to illness and ask anyone who is presenting as unwell to go home, or ask parents and caregivers to come and pick the child up." The new normal for early childhood centre communities in which sick children and adults must stay at home, challenges a longstanding issue for the sector that intersects with the above normalisation of early childhood education as a mechanism for freeing up adults for work. The pandemic response highlights the tensions and complexities around the role of the sector in freeing up adults to work. That freedom can require multiple configurations of early learning service attendance for children - including children who are sick. A key and ongoing concern for the sector is then the tensions between participation and health and wellbeing of children and of the teachers who work with children who attend multiple services, and who themselves may be expected to work at multiple services when pandemic restrictions are lifted.

In recognising the importance of managing staff, the Ministry guides employers on 19 August. That Ministry bulletin provided insight into a wide range of issues for teacher wellbeing that should invite essential discussions about the new normal and the new normalisation of the work of teachers. The Bulletin focuses on, in this order, 1) getting the number of staff right, 2) managing learning from home, 3) keeping staff within one bubble in one service, 4) maintaining employee rights such as non-contact time, 5) a reminder to ensure the staff experience a "safe environment," 6) providing alternate duties to staff 
who cannot perform their usual roles, 7) allowing staff to work remotely if travel is limited, and 8) flexible arrangements for staff with children under the age of 14 . Each of these points are essential and ongoing concerns that impact on each teacher, on the centre and its curriculum, on families and communities, and on the nation. Addressing each point also raises questions as to how the nation chooses to prioritise employment conditions. Each expectation requires significant conceptual investment from the nation to allow for better funding and better governance of, for instance, better ratios, better provisions for noncontact time, and better provisions for consistencies in staffing - rather than working to minimum standards constantly (see Gibbons et al., 2016). Most importantly, the pandemic response highlights the importance of a review of policies regarding teachers and children being forced to participate in services when they are unwell. A new normal would, perhaps, involve a new approach to supporting children and teachers when they are unwell.

\section{Myths and realities}

Each bulletin typically begins with a message from Secretary of Education Iona Holsted. For this research, these were read for the tone and substance of key messages to come from the Ministry. Each message can be seen to reiterate key national messages regarding the pandemic response. For instance, when the nation was out of alert level 4 and with no recent community cases, Holsted (4 August 2020) counselled: "It is important that we do not become complacent about our situation." When the Auckland region went back to Level 3: "The shift in alert levels announced by the Prime Minister last night was the last thing any of us wanted to hear, but thank you for the calm and sensible way you have responded to this latest news. It's good to know we are prepared this time but there is information below to remind you about the important things to do under the different alert levels. ... You have done a wonderful job keeping your communities safe throughout the Covid-19 pandemic and I know you are best placed to continue to do so. He waka eke noa" (Holsted, 12 August 2020). Such affirmations also feature in the letter templates to parents. The Ministry provided a templated letter for centres to share with parents, including an introduction in which the Ministry has suggested that centres write "It is pleasing to see how New Zealanders are responding to this latest outbreak by getting tested if unwell, and staying home" (15 August 2020). This regular re-emphasising of the collective experience, and the sharing of positive thoughts, may be a common-sense approach to humanising the bulletins and providing a sense of security and support. At the same time, the tone of 'we must not be complacent' is reminiscent of the propaganda employed during World War Two to govern the war effort in the United Kingdom, which was particularly successful in its 'normalising effect.' Furthermore, the discourse in Europe during the pandemic has been consistently referring to the idea that this pandemic is the worst crisis that Europe and the United Kingdom have faced since World War Two. During the pandemic crises, as with during the war, the government communicates the norms of good citizenship. At the same time, the new norms for good citizenship become a way of measuring who is doing a good job and who is not. In this way citizens can recognise themselves as contributing to the collective effort, and recognise others as not pulling their weight and/or doing their bit for the nation. Offering such templates to services additionally normalises early learning services as vehicles for these messages. Early learning services become normalised as the very 'how' for the normalisation of families. 
DOI: https://doi.org/10.26686/nzaroe.v25.6911

One particularly important role assigned to services involved educating parents on the pandemic facts and alerting parents to the danger of misinformation. The Ministry was particularly concerned during this period that misinformation was being spread. This led to a range of communications focused on what information to trust and how to manage the flow, or flood, of information from at times competing sources. On 21 August the Secretary introduced the bulletin with a comment that it was "particularly disappointing that not only have we had to deal with a resurgence of Covid-19, but also rumours and misinformation." The Ministry put significant emphasis into combatting what it called 'dangerous rumours': "We continue to see misinformation circulating on social media and other forms of media regarding medical testing." The rumour of particular concern is that "children will be taken away from families if they or their family test positive for Covid-19." The Bulletin then states "it is a priority that the child remains safely in the care of their parent or caregiver." Of course, to say that a thing is a priority is not the same as saying it will not happen. Hence, the Bulletin does not dispel the rumour, but rather restates its policy.

There had been much emphasis in the bulletins of a normalisation of the collective experience with the language of 'we are all in this together.' When it comes to rumours and misinformation, the Ministry is clearly concerned with some parents more than others. In an articulation of both togetherness and isolation, the 14 September Bulletin advised: "Misinformation and conspiracy theories have the potential to steer our team of 5 million off course, causing the pandemic to worsen and take hold in our Pasifika communities." Similarly, the 21 August Bulletin provided an update related to return to services aimed at "our NZ Pacific community." The campaigns to get people comfortable with testing recognised that there is a resistance to medical advice and services from some communities more than others - inviting very significant and ongoing questions as to how and why this occurs in the nation's health services and what role early learning services might play. The 14 September Bulletin promotes a specific focus on supporting "Pasifika families and communities" through the development of "a model to help us navigate the sea of information available in our community." The purpose of the website and of the navigation of the sea of information is explained as such:

In these uncertain times how do we navigate the sea of information, and not lose ourselves in a storm of half-truths, misleading statements, and speculation? 2020 has been a hard and confusing year for all of us. In recent times, there has been a lot of misinformation from unreliable sources, that only make this journey we are taking together more difficult. (14 September)

A templated letter for parents underscores the perceived importance of addressing the control of and impact of contrary and unauthorised sources of information.

While we are doing the right things, it is important that we continue to pay attention to the right information. Misinformation is designed to create panic, fear and confusion. Check your source. Get the real deal from the Ministry of Health or Unite Against COVID-19 websites. The Ministry of Education also provides information for schools and early learning services including specific information for parents and caregivers. (14 September) 
DOI: https://doi.org/10.26686/nzaroe.v25.6911

There's a significant irony in this explanation of what misinformation is designed to do. Then:

Our knowledge of COVID-19 is developing quickly. But misinformation spreads further and faster. Be part of the solution. Don't share posts or stories if you're not sure if they're true or aren't from trusted sources like the Ministry of Health or Unite Against COVID-19 websites. (14 September)

Misinformation is given the qualities of a virus that spreads faster than truth. Yet it could be that normalisation produces misinformation through its insistence on collective agreement with little sharing of the actual facts. The Ministry refers to the importance of "reliable sources":

Reliable sources show that COVID-19 and its impacts are real. WE need to wear masks, WE need to physically distance, WE need to get tested if we are unwell, WE need to stay home if we can, and WE need to do this TOGETHER. For ourselves, for our families and for our communities. (14 September)

The emphasis on 'our team' and what 'WE' need to do 'TOGETHER' blurs over the significant distinctions and discriminations in experiences of the virus and of the lockdown measures. While it makes sense to insist that some sources are more reliable than others and to provide guidance in determining the reliability of sources, the manner (the how) of the insistence, stating 'we all' but really meaning, actually only some of us, fails to take seriously other concerns with the experience of being governed in Aotearoa New Zealand. More careful work can be done here. The bulletins themselves are open to criticism of providing misinformation and half-truths as well as carefully managing the information to suit particular agendas rather than to promote the sharing and discussion of information.

In terms of information and misinformation, how do the bulletins deal with particular truths? For that we would like to look at the language around mask wearing. The normalisation of masks was of particular interest with regards to the flow of information and the normalisation of children as non-mask wearers. Dr Bloomfield somewhat famously proposed mask Monday with the intention of normalising masks. However, over time, it became clear that young children were not to wear masks and the information around this reinforced particular normalisations of childhood. The letter template for families on 27 August includes reiteration of hygiene standards at home, that "Public Health officials have advised that children under the age of 6 should not wear face coverings." "Masks are not required in early learning services or schools at Alert Levels 2 or 3" (12 August). "PPE including face coverings are not required or recommended in early learning services" (15 August). In the letter template to parents on 15 August families are also advised that "We know all these things will help to keep our community as safe as possible. Because of these measures being in place, your child does not need to wear a face covering while attending an early learning service."

On 15 August the Ministry shared the following from Dr Caroline McElnay: "We have carefully looked at the evidence around Covid-19 and educational settings, and at the experience of other countries in responding to Covid-19 in these settings to inform the public health advice about face coverings (including masks) for children and young people at school and early learning services." In a cost-benefit analysis, the Ministry explains that masks reduce the spread of the virus, but that early learning centres already have suitable 
measures in places to reduce the spread of infection (with the exception of norovirus in some centres), including the prevention of children and teachers participating in more than one group. The cost to learning is considered far more of an issue:

Overall, we think it is important not to interfere with learning as much as possible, so it's about balancing up the benefits against the potential harms. Early learning or school bubbles at Alert Level 3 already sufficiently reduce the risk of spreading infection without introducing any potential harms or risks from the use of face coverings (such as breathing issues or not properly fitted masks). Based on what we know about face coverings and transmission in children, we are taking this balanced approach at this time. If new evidence emerges, this guidance will be revised. (15 August)

Face coverings then are not the new norm in educational settings because face coverings are believed to interfere with learning. The idea that learning is interfered with if there is a face covering suggests a narrow view of learning. There's no clear explanation of why this is the case - in other words, a half-truth. Here the information is that not being face to face interferes with learning, which then raises concerns about the emphasis on early learning services switching to a distance learning mode. On 27 August the topic of face coverings is revisited. The bulletin explains that there is "emerging international evidence that the use of masks and face coverings can reduce the risk of infected people spreading Covid-19. Masks and face coverings can be particularly useful if there is a risk of undetected community transmission and people are in close proximity to each other, or are unable to physically distance." That evidence led to a requirement for face coverings on public transport. However, children "under the age of 6 should not wear face coverings." There is no clear explanation of why this is the case.

The point here is not to reject the guidance, but rather to question how this guidance addresses the issue of providing reliable information. There's limited explanation of any of these decisions and the evidence that informs them. They appear to be based on particular norms regarding learning and childhood that can be questioned. For instance, given that masks can include scarfs, bandanas, or other fabrics, it seems odd to imply that children under the age of six should not wear a mask and that there might be some impact of wearing masks for the child's learning. Certainly, some children may object to wearing masks, while others might object to being told they cannot wear a mask. The point here is not to come up with a new or better normalisation of mask wearing, but rather to question the way in which the mask wearing guidelines normalise child development and child learning in particular ways. If the advice for adults is to allow for some exemptions in mask wearing based on perceived unsuitability for physical or mental health reasons, this might suggest that for children under the age of six they too could be considered case by case. In the approach taken, all under six years old are considered vulnerable to the negative effects of face coverings, however this is not the argument made, rather the argument is that there's little risk.

The purpose here is not to debate the logic of the regulations or to suggest that some health guidance was incorrect, rather it is important to explore how the health guidance is shared to understand how advice is presented as factual, certain or indisputable. The guidelines are of interest in as much as they are shared in particular ways, and for how they present knowledge about the virus, the pandemic, government, education, care, and so on. 


\section{New normalising in early childhood education}

Notions of participation, wellbeing and truth are all subjected to the new norms of post pandemic discourse and warrant sustained and inclusive attention to support the complexities of governing the early childhood sector. The discussion above provides a reading and some analysis of the bulletins to open up some new senses of new normalisations in this new age of the new normal. As already noted, the purpose is not to suggest that normalisations are intolerable or bad, or that the Ministry bulletins are evidence of nefarious control of a population. Rather, the bulletins offer insights into the complexities of governance and the ways in which governance normalises. More than this, the analysis offers some insights into the different conversations on normalisation that recognises how normalisations change. During the selected months of the pandemic, these normalising shifts included:

1. Some communities are more at risk of being misinformed than others

2. Masks prohibit learning for children under the age of six

3. When there's no pandemic, there's no support to stay home when you are unwell

4. Early childhood teachers are online teachers

5. The early childhood sector is vital to combatting a pandemic, but early childhood teachers are not front-line workers

6. Early learning services play a vital role in the normalisation of families

The challenge for the Ministry and for the sector that is evident in the bulletins is a challenge of facts and truths, policies and processes. In an era when there is a little more sensitivity to the nature and impact of truth, referred to in scholarship and media as the post-truth problem, it is certainly worth considering what is being normalised here around a knowledge of, and relationship to, the available facts. That sharing details about a pandemic can be refused as a conspiracy in some communities is an educational problem to explore and respond to. This exploration includes the very role normalisation plays in the understanding and reception of truths and facts.

Why worry about this? That the Ministry is providing many truths and realities while at the same time warning the sector about rumours and lies, demands thinking about knowledge and truth. Foucault's attention to these means his work and its application in ECE is particularly relevant to supporting (if not immunising) the sector. The bulletins enable "talk and thought about what is normal" (Ailwood, 2003, p. 293) and how this talk and thought produces particular behaviours, relationships, and experiences. Let us start, perhaps, with the idea of being essential. Early childhood is not talked about as an essential service, it is talked about as a way to ensure essential services are staffed. How does that thinking impact on the sector in realising its responsibilities to the nation?

\section{References}

Ailwood, J. (2003). Governing early childhood through play. Contemporary Issues in Early Childhood, 4(3), 286-299.

Derrida, J. (1978). Writing and difference. University of Chicago Press. 
DOI: https://doi.org/10.26686/nzaroe.v25.6911

Fendler, L. (2017). Foucault's work in philosophy and history of education, reception and influence of. In M. Peters (ed.), Encyclopedia of Educational Philosophy and Theory (pp. 851-856). Springer.

Foucault, M. (1980). Power/knowledge: Selected Interviews and other writings (19721977). Harvester Press.

Gibbons, A. (2020). The negation of babysitting: Deconstruction and care in early childhood. Global Studies of Childhood, 10(4), 358-367.

Gibbons, A., Farquhar, S., \& Tesar, M. (2016). Working conditions in the early childhood education sector. Briefing papers for the Policy Observatory.

http://briefingpapers.co.nz/working-conditions-in-the-early-childhood-educationsector/

Gur-Ze'ev, I. (2017). Knowledge, violence, and education. In M. Peters (ed.), Encyclopedia of Educational Philosophy and Theory (pp. 1222-1226). Springer.

Jandrić, P., Hayes, D., Truelove, I., Levinson, P., Mayo, P., Ryberg, T., Monzo, L. D., Allen, Q., Stewart, P. A., Carr, P. R., Jackson, L., Bridges, S., Escano, C., Grauslund, D., Manero, J., Lukoko, H. O., Bryant, P., Fuentes-Martinez, A., Gibbons, A., ... Hayes, S. (2020). Teaching in the age of Covid-19. Postdigital Science and Education, 2(3), 1069-1230. https://doi.org/10.1007/s42438-020-00169-6

Juelskjær, M., \& Schwennesen, N. (2012). Intra-active entanglements - An interview with Karen Barad. Kvinder, Køn \& Forskning, 1-2, 10-23.

Malone, K., Tesar, M., \& Arndt, S. (2020). Theorising posthuman childhood studies. Springer.

Marshall, J. (1989). Foucault and education. Australian Journal of Education, 33(2), 99113.

Ministry of Education. (2002). Ngā huarahi arataki strategic plan for early childhood education: Pathways to the future. Author.

Ministry of Education. (2004). He whakamōhiotanga ki Kei Tua o te Pae: An introduction to Kei tua o te pae. Learning Media.

Ministry of Education. (2019). He taonga te tamaiti every child a taonga: Early learning action plan 2019-2029. Author.

Ministry of Education. (2020, August 4). He pānui kōhungahunga the early learning bulletin. https://mailchi.mp/education/early-learning-bulletin-4-august-2020

Ministry of Education. (2020, August 12). He pānui kōhungahunga the early learning bulletin. https://mailchi.mp/education/early-learning-bulletin-4-august-715674 
DOI: https://doi.org/10.26686/nzaroe.v25.6911

Ministry of Education. (2020, August 15). He pānui kōhungahunga the early learning bulletin. https://mailchi.mp/education/early-learning-bulletin-15-august-715810

Ministry of Education. (2020, August 19). He pānui kōhungahunga the early learning bulletin. https://mailchi.mp/education/early-learning-bulletin-19-august-2020

Ministry of Education. (2020, August 21). He pānui kōhungahunga the early learning bulletin. https://mailchi.mp/education/early-learning-bulletin-21-august-2020

Ministry of Education. (2020, August 27). He pānui kōhungahunga the early learning bulletin. https://mailchi.mp/education/early-learning-bulletin-27-august-2020

Ministry of Education. (2020, September 14). He pānui kōhungahunga the early learning bulletin. https://mailchi.mp/education/early-learning-bulletin-14-september-2020

Ministry of Education. (2020, October 5). He pānui kōhungahunga the early learning bulletin. https://mailchi.mp/education/early-learning-bulletin-5-october-2020

Ministry of Education. (2020, November 3). He pānui kōhungahunga the early learning bulletin. https://mailchi.mp/education/early-learning-bulletin-3-november-2020

Ministry of Education. (2020, November 24). He pānui kōhungahunga the early learning bulletin. https://mailchi.mp/education/early-learning-bulletin-24-november-2020

Moss, P. (2015). There are alternatives! Contestation and hope in early childhood education. Global Studies of Childhood, 5(3), 226-238.

New Zealand Herald (2020, August 31). Covid 19 coronavirus: Auckland's new, 'new normal' - What level 2.5 means for you. https://www.nzherald.co.nz/nz/covid-19coronavirus-aucklands-new-new-normal-what-level-25-means-foryou/5MAJVGIFGDGTXATULHFXHQSWRI/

Niesche, R. (2017). Foucault and educational administration. In M. Peters (ed.), Encyclopedia of Educational Philosophy and Theory (pp. 837-842). Springer.

Noddings, N. (2002). Starting at home: Caring and social policy. University of California Press.

Orchard, J., Gaydon, P., Williams, K., Bennett, P., D’Olimpio, L., Çelik, R., Shah, Q., Neusiedl, C., Suissa, J., Peters, M. A., \& Tesar, M. (2020). Philosophy of education in a new key: A 'Covid Collective' of the philosophy of education society of Great Britain (PESGB). Educational Philosophy and Theory, 1-14. https://doi.org/10.1080/00131857.2020.1838274

Peters, M. A., Arndt, S., Tesar, M., Jackson, L., Hung, R., Mika, C., Ozolins, J. T., Teschers, C., Orchard, J., Buchanan, R. and Madjar, A. (2020). Philosophy of education in a new key: A collective project of the PESA executive. Educational Philosophy and Theory, 1-22. https://doi.org/10.1080/00131857.2020.1759194 
Sajadich, N. (2017). Foucault and educational theory. In M. Peters (ed.), Encyclopedia of Educational Philosophy and Theory (pp. 843-846). Springer.

Smeyers, P. (2010). Child rearing in the "risk" society: On the discourse of rights and the "Best interests of a child." Educational Theory, 60(3), 271-284. https://doi.org/10.1111/i.1741-5446.2010.00358.x

Tesar, M. (2014). My feelings: Power, politics and childhood subjectivities. Educational Philosophy and Theory, 46(8), 860-872.

https://doi.org/10.1080/00131857.2013.7814966

Professor Andrew Gibbons is an early childhood teacher, teacher educator and Professor at the School of Education. He has worked in journalism, in the social services in England and in early childhood education in Auckland. Andrew works on the Bachelor of Education, Bachelor of Arts, Master of Education, and Doctor of Philosophy programmes at the School of Education. He is an executive committee member of the Association of Visual Pedagogies, member of the Philosophy of Education Society of Australasia, and co-leader of the Editors' Collective.

Email: andrew.gibbons@aut.ac.nz

ORCiD: https://orcid.org/0000-0002-0847-5639

Marek Tesar is an Associate Professor and the Associate Dean International, and Academic Head designate at the Faculty of Education and Social Work, University of Auckland. His expertise is in early childhood education and childhood studies in both New Zealand as well as in cross-country contexts. His work focuses on educational policy, philosophy, pedagogy, methodology and curriculum, and draws on his background as a qualified teacher as well as his extensive knowledge of international education systems. His scholarly work has received numerous prestigious national and international awards and accolades. Currently, he is President of the Philosophy of Education Society of Australasia (PESA), and chairs the Steering Committee of the Reconceptualising Early Childhood Education society (RECE).

Email: m.tesar@auckland.ac.nz

ORCiD: https://orcid.org/0000-0001-7771-2880 